\title{
A differential etching and magnetic separation approach to whole-rock potassium-argon dating of basaltic rocks
}

\author{
Peter Horn* and Dieter Müller-Sohnius \\ Mineralogisch-Petrographisches Institut der Universität München, Theresienstrasse 41, \\ 8000 München 2, FRG
}

(Received July 12, 1988; Accepted October 5, 1988)

\begin{abstract}
In this pilot study an extension of whole-rock K-Ar dating methods of volcanic rocks is established. Whole-rock sieve fractions $80-250 \mu$ m of basaltic rocks were etched for durations up to $20 \mathrm{~min}$ in $6 \%$ hydrofluoric acid at room temperature and cleaned ultrasonically. Aliquots thereof were further separated into magnetic and nonmagnetic subfractions.

Conventional $\mathrm{K}-\mathrm{Ar}$ analyses reveal disturbed $\mathrm{K}-\mathrm{Ar}$ systems in the rocks and nonmagnetic fractions, as both Ar loss and extraneous Ar are observed. Ar loss occurred in high-potassium matrix phases, while olivine- and clinopyroxene-phenocrysts, which are mostly xenocrysts, are carriers of extraneous Ar.

Magnetic fractions etched for 5 min exhibit no significant Ar losses nor extraneous Ar and show internally consistent ages or age concordance with minerals of proven suitable quality for $\mathrm{K}-\mathrm{Ar}$ dating. The method is suited for unravelling extrusion ages of volcanic rocks in which the whole-rock $\mathrm{K}-\mathrm{Ar}$ system is disturbed and should be applied whenever adequate minerals cannot be separated for dating purposes.

The eight basaltic rocks investigated stem from four localities in the Hocheifel Area, FRG; all of them show significant disturbances in their $\mathrm{K}-\mathrm{Ar}$ system.
\end{abstract}

\section{INTRODUCTION}

To obtain a reliable $\mathrm{K}-\mathrm{Ar}$ age, dating of volcanic rocks should be performed for at least two species of separated minerals with high $\mathrm{Ar}$ retentivity. Concordant age values can then be considered to date the eruption of the lava. When it is not possible to separate minerals, one is restricted to dating whole-rock samples, where one must principally be aware of possible radiogenic Ar losses and Ar additions, which depend on the rock's history, including processes of magma generation. Extraneous $\mathrm{Ar}$, either excess- or inherited Ar, may easily remain unrecognized. The same holds true for Ar losses. The latter preferably occur in rock phases with small grain sizes. Furthermore, the formation of secondary minerals from primary ones by the action of hydrothermal solutions, ultimately by weathering, is usually accompanied by Ar loss. Microscopic inspection of thin sections from a rock can often suggest possible disturbances in its Ar inventory. Quantitative information, however, must be found by other means.

Of all the methods for identifying disturbances in the $\mathrm{K}-\mathrm{Ar}$ system of a rock, the ${ }^{40} \mathrm{Ar}$ ${ }^{39} \mathrm{Ar}$ stepwise-heating technique has the best potential for unravelling such distortions. It has been successfully applied to lunar, meteoritic, and terrestrial volcanic whole-rock samples. Despite the many advantages of this technique over conventional $\mathrm{K}-\mathrm{Ar}$ dating, under some circumstances serious experimental artifacts are introduced by the applied neutron dose, in par-

\footnotetext{
${ }^{*}$ Present address: Institut fur Allgemeine und Angewandte Geophysik der Universität München; Theresienstrasse 41, 8000 München 2
} 
ticular separation of recoiling ${ }^{39} \mathrm{Ar}$ from lattice sites of ${ }^{40} \mathrm{Ar}_{\text {rad }}$ (Huneke and Smith, 1976), but also partial loss of ${ }^{39} \mathrm{Ar}$ and changes in Ar-retention properties of minerals and glasses. The latter seems to be important in dating old lunar and meteoritic rocks where high neutron-doses $\left(\geq 10^{18} \mathrm{n} / \mathrm{cm}^{2}\right)$ are necessary (Horn et al., 1975). Neutron-induced artifacts are all the more pronounced the larger the differences in grain size and K-concentration of minerals with differing Ar-retentivities, given that grain sizes are small ( $\leq 50 \mu \mathrm{m}$ ) for a significant fraction of $\mathrm{K}$-bearing phases. Such conditions are most commonly met in extrusive basaltic rocks where K-poor phenocrysts are embedded in a fine-grained $\mathrm{K}$ rich matrix. ${ }^{39} \mathrm{Ar}$-recoil effects are the main source of disturbances in ${ }^{40} \mathrm{Ar}-{ }^{39} \mathrm{Ar}$ dating of terrestrial rocks and often result in hummocky ${ }^{40} \mathrm{Ar} /{ }^{39} \mathrm{Ar}$-"plateaus" or drop-offs from the plateaus (e.g. Dalrymple and Lanphere, 1974; Seidemann, 1978; Fuhrmann et al. 1987).

In view of the difficulties inherent in ${ }^{40} \mathrm{Ar}-$ ${ }^{39} \mathrm{Ar}$ dating of volcanic rocks, a differential dissolution technique followed by conventional $\mathrm{K}$-Ar dating is presented here. The rationale is that through acid-etching of whole-rock grains those minerals or glasses which have lost radiogenic Ar, due to small grain sizes or weathering, are preferentially dissolved. This would lead to higher $\mathrm{Ar} / \mathrm{K}$ ratios, hence ages, of the residues. Etching potentially results in concordant ages for certain rock subfractions, which would then be equal to the extrusion age when extraneous argon is not present. The etching procedure is complemented by magnetic separation of whole-rocks into a magnetic fraction comprising matrix phases, and a nonmagnetic fraction which consists mainly of phenocrysts such as olivine and pyroxene which are frequently carriers of extraneous Ar.

Etching of whole-rocks prior to $\mathbf{K}-\mathbf{A r}$ analysis is not a new technique. Kaneoka (1971) was the first to publish results in this area. He systematically applied different etchants to altered deep-sea basalt and concluded that etching is suitable for removing rock phases which have suffered Ar loss.

\section{Basic Prerequisites for the Differential Etching Technique}

For a successful application of the etching technique to rocks, different dissolution rates of the rock constituents are essential. Shimizu (1974) made use of this effect to determine partition coefficients for alkalies between clinopyroxene and matrix ("differential dissolution technique, DDT"). In an article on the same subject, Watson et al. (1987) demonstrated that pyroxenes etch very slowly in comparison to basaltic glass.

We determined relative weight losses by etching both a whole-rock sample and those minerals typically found as phenocrysts in the basaltic rocks investigated in our study, i. e. titaniumaugite, olivine, and bytownite. Etching rates differ by as much as a factor of 7 for the specimen, in the grain size range from $60-80 \mu \mathrm{m}$ (Table 1). High etching rates for the whole-rock are due to rapid dissolution of mesostasis-glass, devitrification products (predominantly clay minerals), analcite, and fine-grained matrix and mesostasis minerals. These results are in agreement with those of laboratory experiments on weathering phenomena (Gislason and Eugster, 1987).

Etching should affect $\mathrm{Ar}$ and $\mathrm{K}$ from all minerals involved proportionally, because the radiogenic ${ }^{40} \mathrm{Ar}$ atoms which follow electron capture in ${ }^{40} \mathrm{~K}$ recoil with an energy of only about 23 $\mathrm{eV}$ and hence change their positions in the crystal structure by only a few atomic spacings (Turner and Cadogan, 1974). Furthermore, Ar isotope fractionation artifacts have not been

Table 1. Weight-losses upon etching and ultrasonic treatment for major rock forming minerals and whole rock $H F 108$

\begin{tabular}{rcccc}
\hline $\begin{array}{c}\text { etching } \\
\text { time }\end{array}$ & $\begin{array}{c}\text { olivine } \\
\text { (wt.\%) }\end{array}$ & $\begin{array}{c}\text { augite } \\
\text { (wt.\%) }\end{array}$ & $\begin{array}{c}\text { bytownite } \\
\text { (wt.\%) }\end{array}$ & $\begin{array}{c}\text { whole rock } \\
\text { (wt.\%) }\end{array}$ \\
\hline $5 \mathrm{~min}$ & 4.2 & 5.0 & 19.1 & 31.1 \\
$20 \mathrm{~min}$ & 7.5 & 7.3 & 32.0 & 35.0 \\
\hline
\end{tabular}

etchant: $6 \%$ hydrofluoric acid at room temperature; ultrasonic treatment: 5 min; grain-sizes: $60-80 \mu \mathrm{m}$ 
detected during stepwise etching experiments on lunar soil plagioclases and pyroxenes (Wieler et al., 1986).

From these observations and experiments we conclude that the etching procedure does not lead to shifts in naturally existing $\mathrm{Ar} / \mathrm{K}$ and $\mathrm{Ar}$ isotopic ratios in whole-rocks, minerals and glasses. Etching with hydrofluoric acid (as used in this study) was successfully applied to a variety of basaltic rocks and minerals from Brazil, Egypt, Sudan and Germany: ages of etched rock and mineral fractions show internal age concordance or agreement with ages obtained by other dating methods (Horn et al., 1988; Saradeth et al., 1989; Müller-Sohnius et al., 1989). No undesirable effects on ages have been found by hydrofluoric acid treatments of feldspars to remove adhering glass particles before $\mathrm{K}-\mathrm{Ar}$ analysis (Evernden and Curtis, 1965). Minute whole-rock fragments of basaltic composition from the Moon, which had to be liberated from solar-wind impregnated rims by $\mathrm{HF}-\mathrm{H}_{2} \mathrm{SO}_{4}$ etching for dating purposes, also showed no alteration in their original $\mathrm{K}-\mathrm{Ar}$ inventory (e.g. Horn et al., 1975).

These results encouraged us to investigate this subject further. Here we present results obtained from eight basaltic rocks from the Hocheifel Area, FRG (Table 2), which were etched by acid and separated magnetically before KAr analyses.

\section{Experimental Procedures}

A flow-chart of the sample preparation and the experimental steps is given in Fig. 1.

Conditions for etching: $6 \%$ solution of hydrofluoric acid (at room temperature) was chosen as etchant because it dissolves mesostasis and other matrix phases while the phenocrysts remain relatively unaffected (Table 1). Under these conditions, etching was slow enough to facilitate sample handling. Fractional weight-losses dur-

Table 2. Characterization of analysed rocks

\begin{tabular}{|c|c|c|c|c|c|}
\hline $\begin{array}{l}\text { Sample No.; } \\
\text { Locality }\end{array}$ & Sample Type ${ }^{a}$ & Phenocrysts $^{b}$ & Groundmass $^{b}$ & $\begin{array}{l}\text { Major K-bearing } \\
\text { Mineral Phases }^{c}\end{array}$ & Xenocrysts $^{d}$ \\
\hline $\begin{array}{l}\text { HF 44-3 } \\
\text { Nürburg }\end{array}$ & tephrite & $11 \%$; cpx; sym; & $\begin{array}{l}89 \% \text {; pl; cpx; } \\
\text { ol; op; meso; }\end{array}$ & pl; afsp; meso; & rare \\
\hline $\begin{array}{l}\text { HF } 108 \\
\text { Hochbermel }\end{array}$ & $\begin{array}{l}\text { nepheline- } \\
\text { basanite }\end{array}$ & $\begin{array}{l}26 \% ; \text { ol: } \mathrm{cpx}= \\
1: 2\end{array}$ & $\begin{array}{l}74 \% ; \mathrm{cpx} ; \mathrm{pl} ; \\
\text { afsp; ol; bi; } \\
\text { meso; op; }\end{array}$ & afsp; pl; meso; & abundant \\
\hline $\begin{array}{l}\text { HF } 364 \\
\text { Bittberg }\end{array}$ & $\begin{array}{l}\text { olivine- } \\
\text { nephelinite }\end{array}$ & $\begin{array}{l}30 \% ; \text { ol: } \mathrm{cpx}= \\
3: 1 ;\end{array}$ & $\begin{array}{l}70 \% \text {; cpx; bi; } \\
\text { afsp; neph; } \\
\text { bi; meso; op; }\end{array}$ & $\begin{array}{l}\text { afsp; neph; meso; } \\
\text { bi; }\end{array}$ & $\begin{array}{l}\text { very abun- } \\
\text { dant }\end{array}$ \\
\hline $\begin{array}{l}\text { HF 3-1 } \\
\text { Höchstberg }\end{array}$ & $\begin{array}{l}\text { nepheline } \\
\text { basanite }\end{array}$ & ol; cpx; & $\begin{array}{l}\text { cpx; pl; ol; } \\
\text { afsp; bi; op; } \\
\text { meso; }\end{array}$ & afsp; pl; meso; & rare \\
\hline $\begin{array}{l}\text { HF 3-2 } \\
/ 1\end{array}$ & $\prime \prime$ & $\prime \prime$ & $" 1$ & $" \prime$ & $\prime \prime$ \\
\hline $\begin{array}{l}\text { HF 3-11 } \\
/ /\end{array}$ & " & " & "l & $\prime \prime$ & $\prime \prime$ \\
\hline $\begin{array}{l}\text { HF 3-K } \\
/ /\end{array}$ & $\begin{array}{l}\prime \prime \\
\text { (+pyroxenite) }\end{array}$ & cpx; idd; & $\prime \prime$ & " & abundant \\
\hline $\begin{array}{l}\mathrm{HF} \\
\prime \prime\end{array}$ & (+ pyroxenite) & cpx; ol; & " & $\prime \prime$ & $" \prime$ \\
\hline
\end{tabular}

${ }^{a}$ nomenclature after Huckenholz (1983)

${ }^{b}$ percentages by weight; cpx=clinopyroxene; ol=olivine; pl=plagioclase; afsp=alkali-feldspar; neph=nepheline; bi=biotite; op=opaques; sym=symplectite of amphibole, rhoenite, cpx, ol, pl; meso=mesostasis with glass, devitrified glass, neph, zeolites, analcite; idd=iddingsite 'phases which contribute significantly to $K$-inventory of whole rock ${ }^{d}$ fragments of spinel peridotites and pyroxenites 


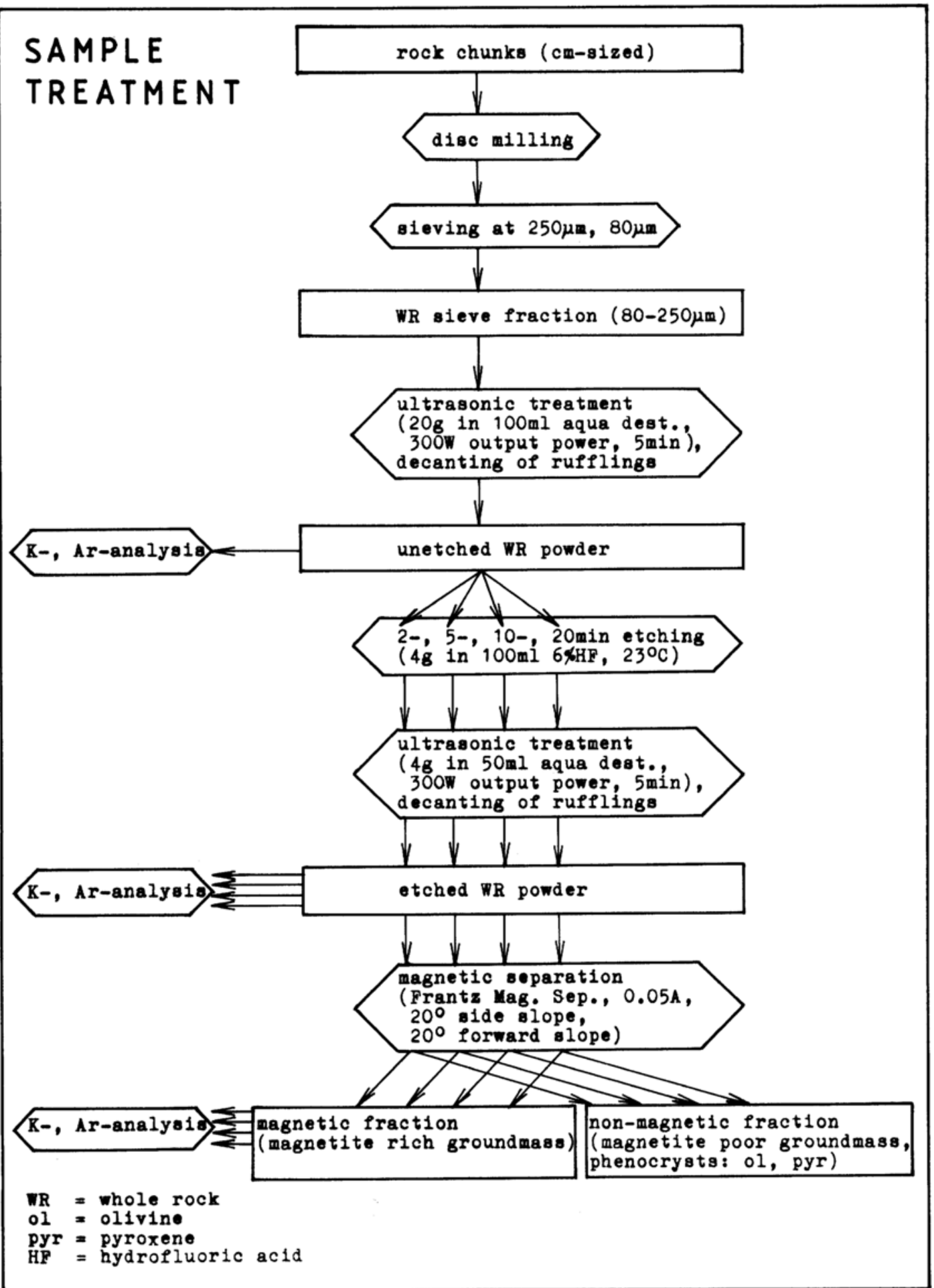

Fig. 1. Flow-chart for sample preparation and sample treatment. 
ing etching (Tables 1, 3 and 4) comprise both chemically dissolved material as well as finegrained debris which broke off the rock particles under ultrasonic treatment and was washed away by repeated decanting of the suspensions.

Ultrasonic cleaning of samples: Ultrasonic treatment is essential in the case of etched samples, in order to remove very fine-grained particles and newly formed fluorides, because they have high surface to volume ratios which result in high atmospheric Ar contributions to total Ar. Because these contaminations are not easily reproducible, we refrain from presenting analyticel data. In one case (sample HF 3-11, Table 4), where etched residues of whole-rock still had high air-Ar contents after $5 \mathrm{~min}$ of ultrasonic agitation, an aliquot was treated for $20 \mathrm{~min}$. As expected, contribution of air-Ar dropped significantly. In general, $5 \mathrm{~min}$ ultrasonic treatment was sufficient to keep air-Ar at reasonably low levels; this is the reason why no systematic dependence of air-Ar on etching time is observed (Tables 3 and 4).

Magnetic separation: Whole-rock fractions, unetched and etched, were split into magnetic and non-magnetic subfractions at low magnetic field strengths in a FRANTZ ${ }^{\circledR}$ magnetic separator (Fig. 1 and Tables 3 and 4). Almost all phenocrysts from the rocks were concentrated in the nonmagnetic separates. A considerable fraction (not quantified) of the phenocrysts are xenocrysts, according to microscopic evidence. Matrix fragments with relatively low magnetic mass-susceptibilities are also found in these fractions. Groundmass and mesostasis are enriched in the magnetic fractions. Incompatible $\mathrm{K}$ is concentrated in these typical late-stage solidification products of volcanic rocks. Hence, $\mathrm{K}-\mathrm{Ar}$ inventories of whole-rocks are dominated by this material (Tables 3 and 4).

Potassium and argon analyses: Potassium was analyzed by flame-spectrophotometry on solutions of approx. $1 \mathrm{ppm} \mathrm{K}$ concentration and $2000 \mathrm{ppm}$ of cesium as ionization buffer. Argon was determined by direct calibration mass-spectrometry in static mode. Duplicate analyses for $\mathrm{K}$ and $\mathrm{Ar}$ were performed on aliquots of each sample; arithmetic means of the results were used in calculating ages. Sample weights were chosen to fulfill statistical requirements for the given grain sizes and mineralogical compositions and were varied by a factor of approximately two for duplicates. For decay constants, accuracy and precision of analyses see captions to Tables 3 and 4, and Müller-Sohnius et al. (1989). For ages given here precision is $\pm 1.6 \%$ ( 1 sigma) and is valid for internal comparison of results; for comparison with ages obtained by other laboratories or dating methods an Ar calibration uncertainty of $\pm 1.2 \%$ must be taken into account. Enhanced errors of 3.4\% ( $1 \sigma$ rel.) for the ages of magnetic fractions will be explained in the relevant chapter.

\section{SAMPLES INVESTIGATED}

Samples were selected from four localities of the Hocheifel Volcanic Province, FRG. Samples HF 44-3, HF 108 and HF 364 were considered most suitable for the experiments because they comprise different rock types with differences in grain size, phenocryst abundance, and modal composition (Table 2). All samples appeared well-preserved or "fresh", both macroscopically and in thin section. The HF 3 sample series and HF 102 stem from one single locality (Höchstberg, Table 2) and seem to belong to three eruptive events, according to field evidence (Bussmann, 1981). Rock HF $3-\mathrm{K}$ is as unweathered as the other samples but exhibits signs of post-volcanic alterations such as replacement of olivine by "iddingsite/bowlingite".

\section{Analytical Results and Discussions}

Results of $\mathrm{K}$ and $\mathrm{Ar}$ analyses and calculated ages are presented in Tables 3 and 4 together with information about etching duration, magnetic type and relative weights for residues from etchings. In Fig. 2, these data for rocks HF 44, HF 108 and HF 364 are shown, normalized 


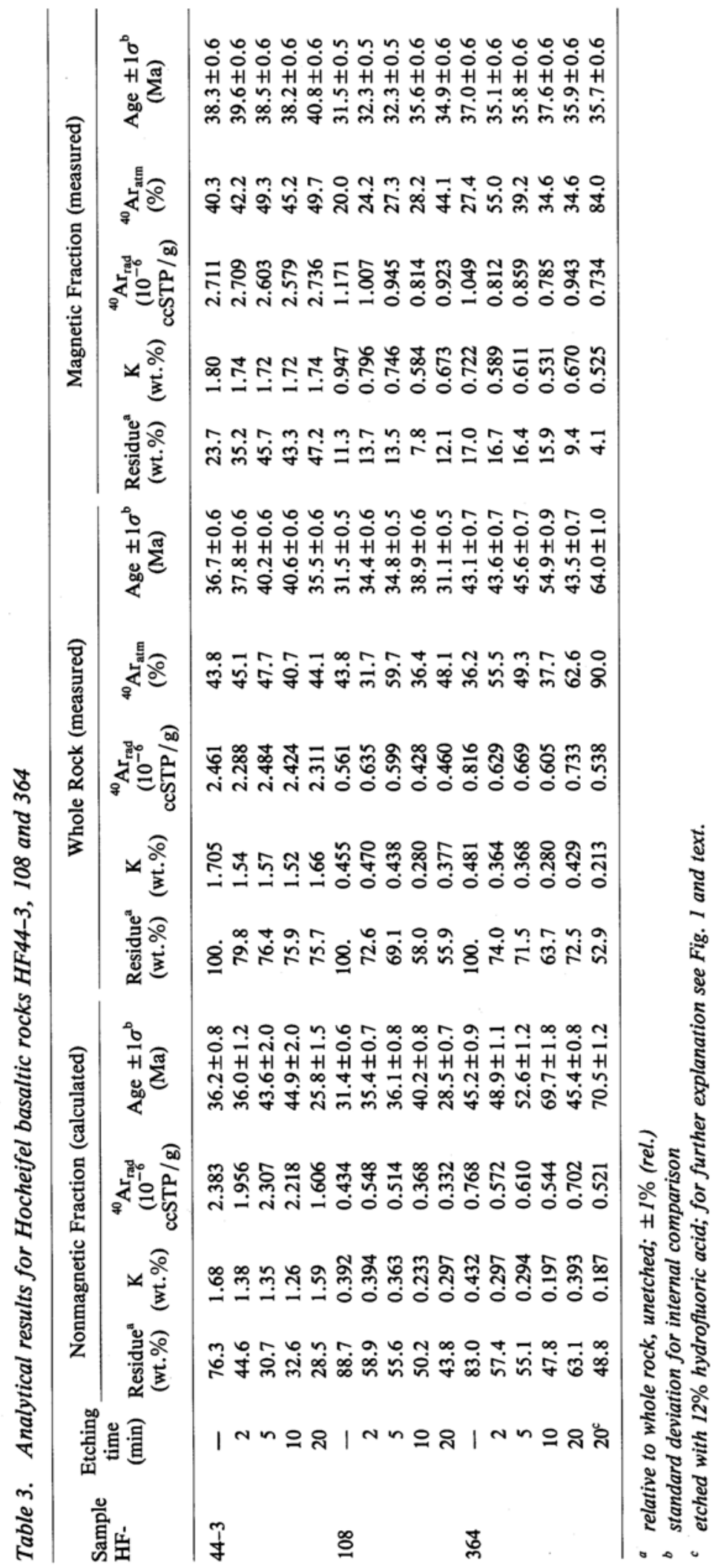




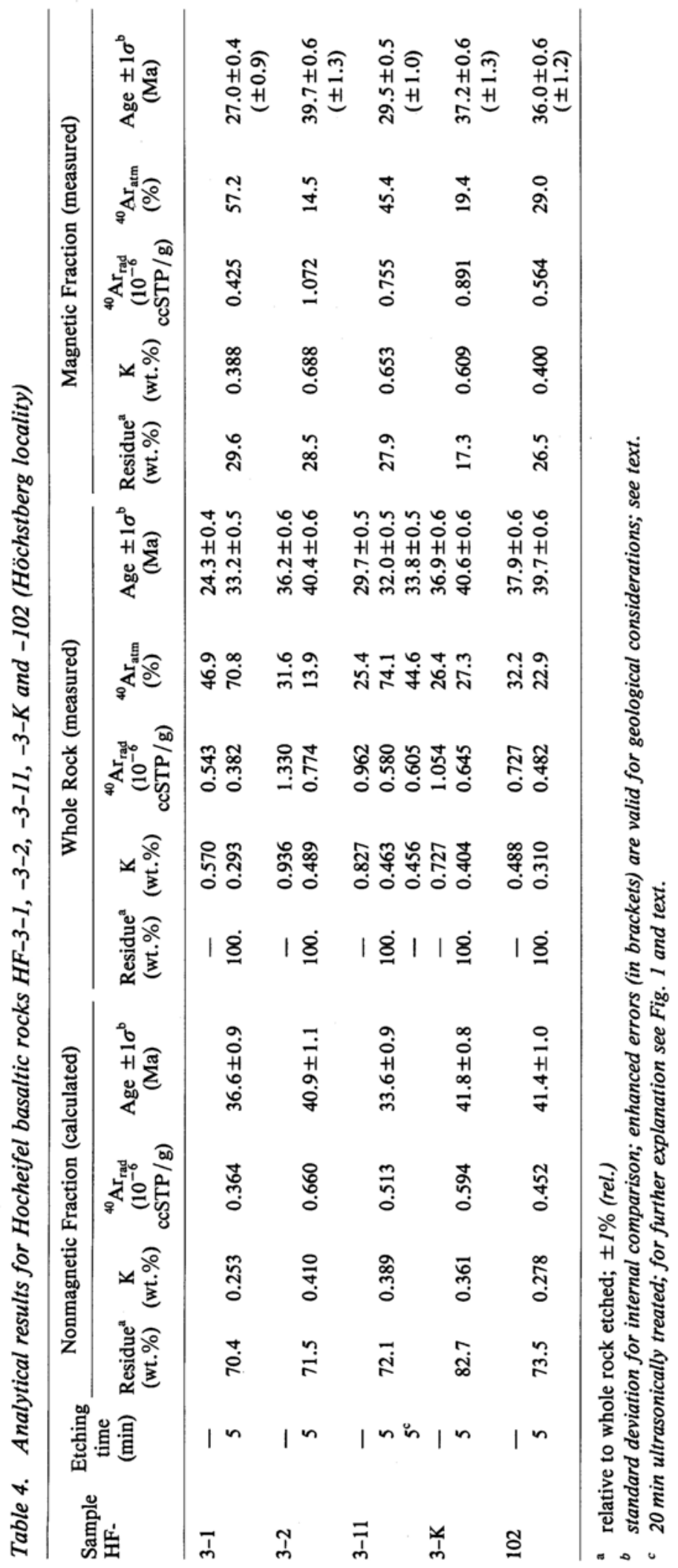



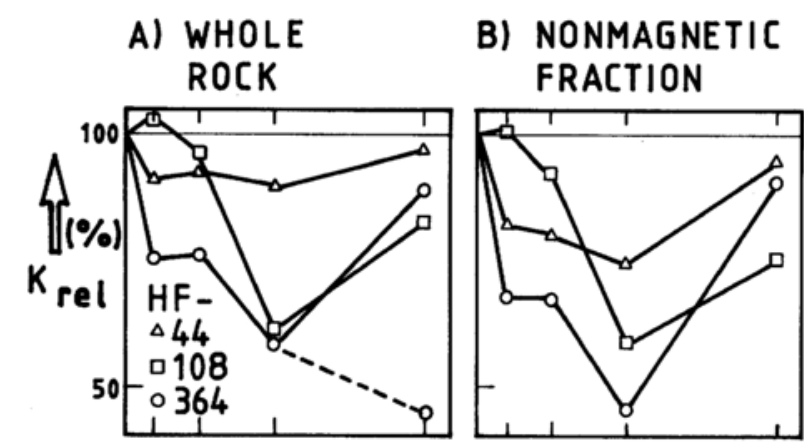

\section{C) MAGNETIC FRACTION}
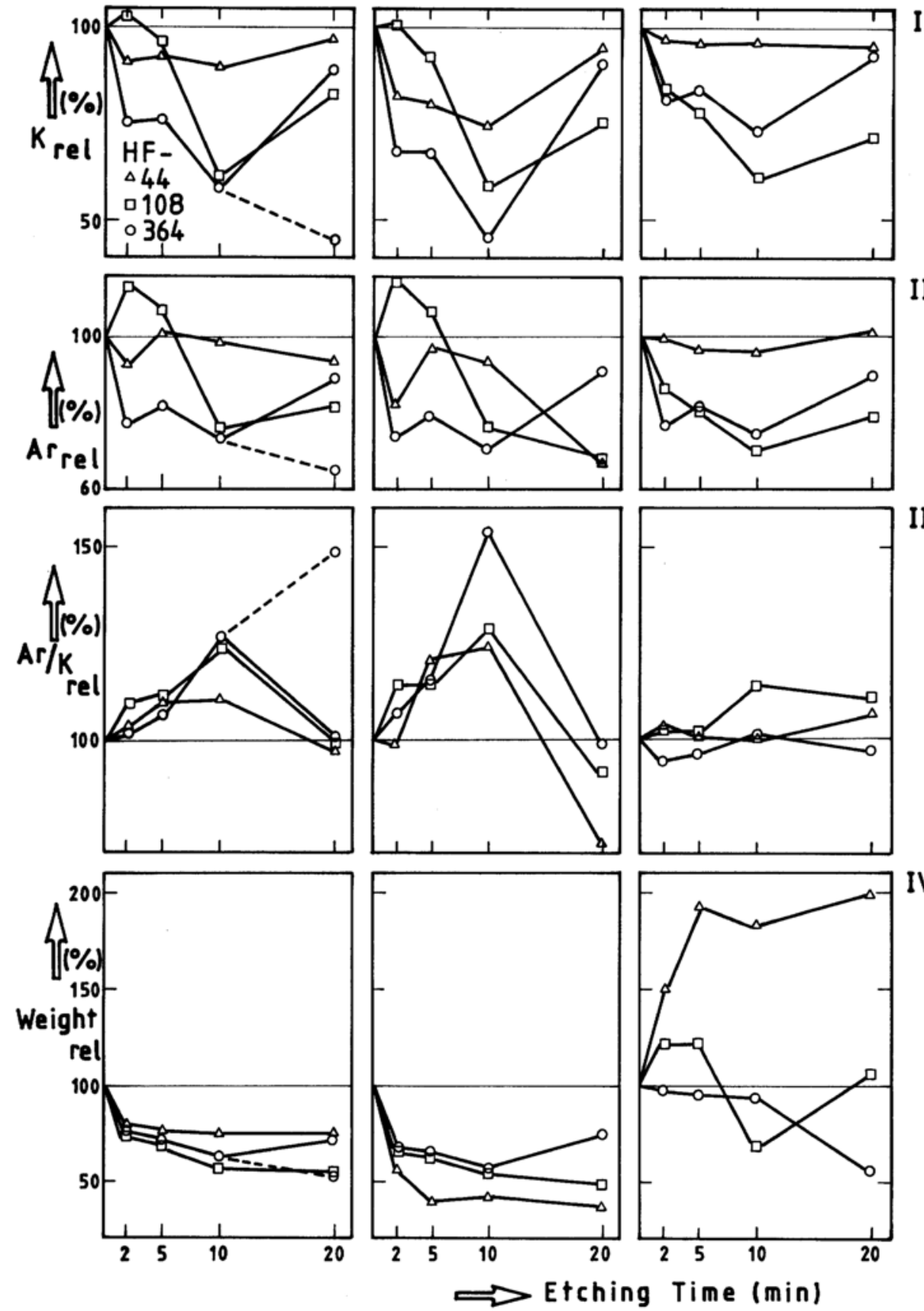

Fig. 2. Relative variations of $K$ concentrations (I), Ar concentrations (II), Ar/K ratios (III) and weights of etching residues (IV) in relation to etching time. The ordinate values are relative to the equivalent unetched whole-rocks or whole-rock subfractions. The samples were etched in 6\% hydrofluoric acid (solid lines); a 20 min. etched aliquot from rock HF 364 was etched in $12 \%$ hydrofluoric acid (dashed line, see text). Values for nonmagnetic fractions are calculated from those for whole-rock and magnetic fractions. Ar/K ratios for magnetic fractions (C III) show the smallest fluctuations despite large variations in Ar and $\mathrm{K}$ concentrations and weights. 
to data for the equivalent unetched fractions.

Effects of etching: Relative weights of etching residues are shown in Fig. 2/IV. A decrease in residual sample weight with etching time is observed. $\mathrm{K}$ concentrations of etched residues also decrease, indicating that high- $\mathrm{K}$ phases are preferably removed (Fig. 2/I). The fact that relative weight losses and $\mathrm{K}$ concentrations do not decrease steadily with etching time can be explained qualitatively. Apart from chemical dissolution, whole-rock particles decay into smaller fragments. These are further dissolved or reduced in size, depending on their primary grain sizes end modes of intergrowth. They behave differently upon ultrasonic agitation and decanting and during magnetic separation (in a FRANTZ ® magnetic separator not only masssusceptibilities are critical but also grain forms, etc.). Another reason is that etching was not performed stepwise, with one starting material, but rather separate aliquots were etched for different times. Thus, these factors can lead to uneven fractionation of rock constituents during sample processing. However, this does not impair the method. Etching leads to a relative enrichment of magnetic particles in whole-rock fractions by, on average, a factor of 1.7 (Table 3 and Fig. 2/IV C). An effort to trace changes in mineralogical compositions of etched fractions by XRD-techniques failed, because they are beyond the resolution of powder diffractometry. On the other hand, those changes caused by magnetic separation show up readily and are also recognizable under the microscope. During etching chemical dissolution occurs predominantly at high-K sites or phases (Fig. 2/I A, B, C). Equivalent effects on $\mathrm{Ar}$ concentration are shown in Fig. 2/II A,B,C. The effects of sample treatment on $\mathrm{Ar} / \mathrm{K}$ ratios, which are proportional to ages, will be discussed below.

$K$-Ar systems of whole-rocks and nonmagnetic fractions: $\mathrm{Ar} / \mathrm{K}$ ratios measured for wholerock samples are presented in Fig. 2/III A, and the ages in Table 3. Ratios increase with etching times up to $10 \mathrm{~min}$ for all rocks analyzed; after
20 min of etching they are close to initial values. To see whether this may be explained by slowing down or stopping the effective etching after 10 $\min$ in $6 \%$ hydrofluoric acid, aliquots from one sample (HF 364) were etched strongly in $12 \%$ acid for $20 \mathrm{~min}$. In fact, stronger etching leads to further dissolution of K-rich material (Fig. 2/I A), while the Ar/K ratio increases (Fig. 2/III A). This is evidence that after $10 \mathrm{~min}$ or more of etching, relatively unaffected whole-rock grains remain, when $6 \%$ hydrofluoric acid is used on the grain size range from $80-250 \mu \mathrm{m}$. Their $\mathrm{Ar} / \mathrm{K}$ ratios, after removal of hitherto etched crusts or deposits of reaction products by ultrasonic cleansing, are the same as those of unetched grains. Variations in $\mathrm{Ar} / \mathrm{K}$ ratios imply significant internal disturbances in the $\mathrm{K}-\mathrm{Ar}$ systems of all rocks investigated here. If they were not disturbed, their ratios would be equal for all subfractions of a given rock. To identify those constituents of the whole-rocks to which $\mathrm{K}-\mathrm{Ar}$ system disturbances can be attributed, we must consider both the magnetic and nonmagnetic fractions; the results for the latter were obtained by balance calculations using analytical results obtained for whole-rock and magnetic sample fractions. By comparison of $\mathrm{Ar} / \mathrm{K}$ ratios in subfractions after different etching times (Fig. 2/III A, B, C), it becomes clear that fluctuations in curves for the whole-rocks are controlled by $\mathrm{Ar} / \mathrm{K}$ ratios in nonmagnetic components. In these fractions, clinopyroxene and olivine phenocrysts dominate the modal composition.

Ar/K ratios of magnetic fractions: Magnetic separates have relatively undisturbed $\mathrm{K}-\mathrm{Ar}$ systems (Fig. 2/III C). In these fractions, which consist predominantly of matrix phases, $\mathrm{Ar} / \mathrm{K}$ ratios are reasonably constant despite variations in $\mathrm{K}$ concentrations which, on average, vary by as much as $23 \%$ in one single rock's magnetic fractions. Because of these different $\mathrm{K}$ concentrations, it cannot always have been the very same material that was analyzed in the various magnetic fractions of the same rock. A similar conclusion can be drawn from different relative weight yields in different etching steps (Fig. 2/IV 
C). The combined effects of etching procedure on weight proportions of nonmagnetic/ magnetic fractions to whole-rocks, and ages are presented in a diagram in which $\mathrm{Ar} / \mathrm{K}$ ratios and $\mathrm{K}$ proportions in residues of the different etching steps are shown (Fig. 3). Nonmagnetic separates show a large scatter in $\mathrm{Ar} / \mathrm{K}$ ratios while those from magnetic fractions are reasonably stable, though $\mathrm{K}$ proportions are very different (e.g. HF 44). Slight fluctuations in $\mathrm{Ar} / \mathrm{K}$ ratios for the latter result from Ar losses and extraneous Ar. In these cases, etching of phases with Ar loss was incomplete and some phenocrysts with extraneous Ar have not been sorted out by magnetic separation because they were embedded within the matrix, as can be seen under the microscope.

In Fig. 4/A, B, C mean relative changes in $\mathrm{Ar} / \mathrm{K}$ ratios per time are plotted against etching time for all samples (that is the average slope from individual curves of $\mathrm{Ar} / \mathrm{K}$ vs. etching time from Fig. 2/III). It can be seen that the smallest relative changes in ratios would appear in magnetic separates if they were etched for 1 to $3.5 \mathrm{~min}$, as in this range the curve shows an ordinate value of almost zero (dotted line in Fig. $4 / C)$. This implies that groundmass phases in these fractions which have lost Ar were removed completely by etching and that residues show constant $\mathrm{Ar} / \mathrm{K}$ ratios. In the same fraction pyroxene and olivine phenocrysts with extraneous Ar do not contribute significantly to either $\mathrm{K}$ or Ar inventories. As there is a common minimum of uncertainties (hatched area) for changes of $\mathrm{Ar} / \mathrm{K}$ ratios between 2 and $5 \mathrm{~min}$ of etching, we decided to consider the ages of those magnetic fractions which were actually etched for $5 \mathrm{~min}$ as the most probable extrusion age for individual rocks; a further substantial argument is the age concordance of the $5 \mathrm{~min}$ etched magnetic fraction with kaersutite and feldspars which are considered useful for $\mathrm{K} / \mathrm{Ar}$ dating, in the case of sample HF 44-3 (see below). The errors ascribed to ages obtained in this manner are standard deviations calculated from the scatter around the normalized mean for all etched magnetic fractions $(n=13)$ from the three rocks investigated. These enhanced errors were chosen
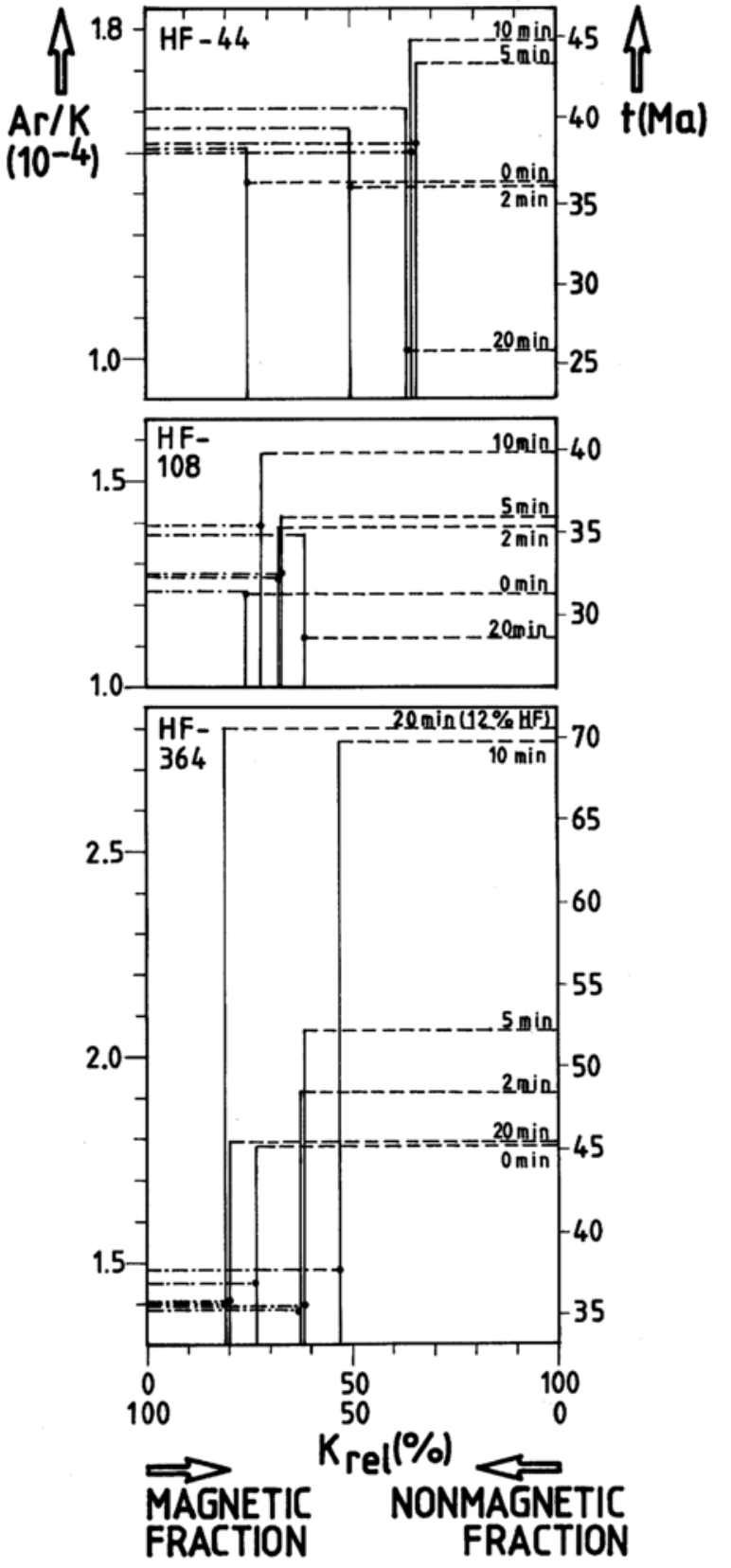

Fig. 3. Ar/K-ratios and ages for magnetic and nonmagnetic etching residuals against whole-rock-proportionate $K$-amounts. The latter were calculated from measured weight yields of magnetic separations and $K$ concentrations. Etching times are indicated. Acid was $6 \%$ unless otherwise stated (sample HF 364, etched for $20 \mathrm{~min}$ ). Independent of their proportions of potassium, magnetic fractions for all three rocks show the smallest scatter of ages. For analytical uncertainties see Table 3. 


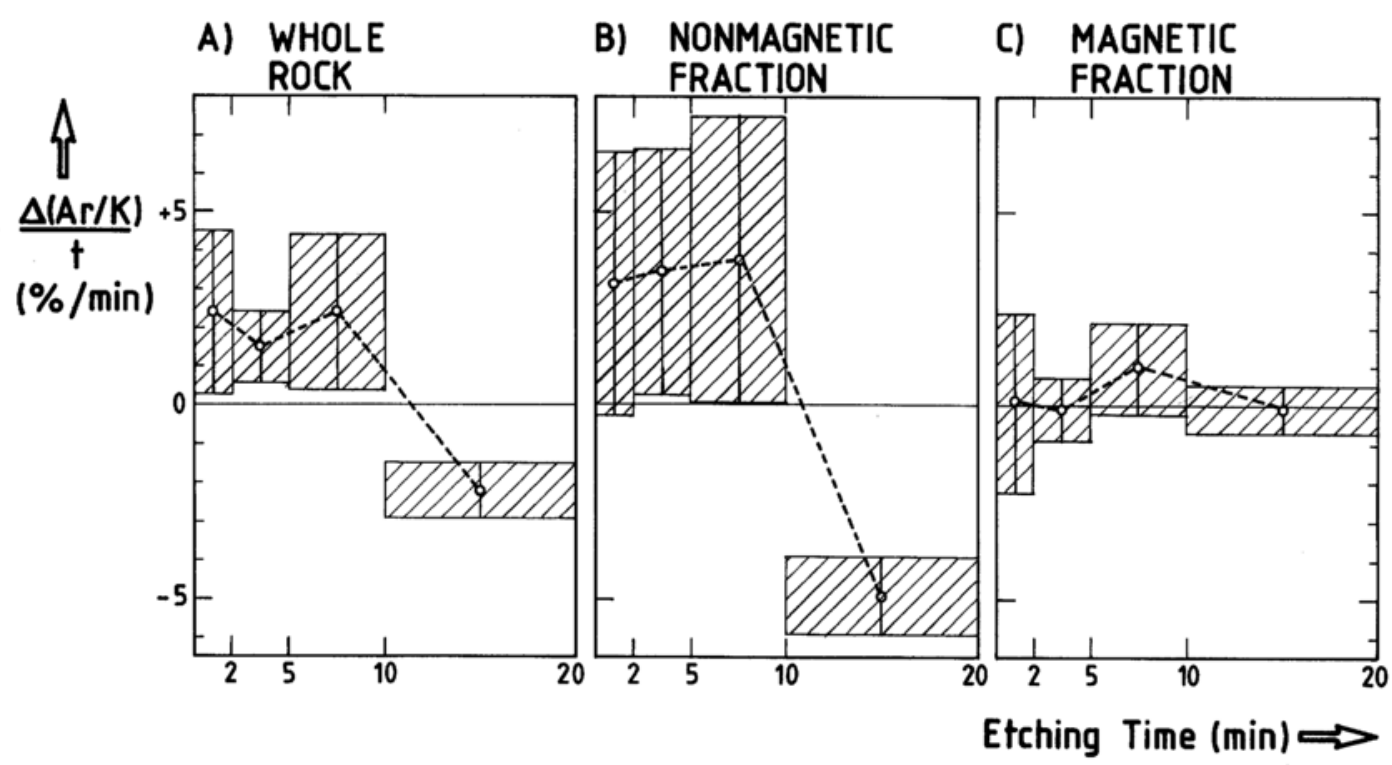

Fig. 4. Changes in Ar/K ratios of residues during etching as derived from the mean slope of curves III $A, B$ and C in Fig. 3 for the three samples. For magnetic fractions etched between 2 and 5 min., uncertainties are relatively low (hatched boxes), while the curve (dashed line) shows an ordinate value of almost zero, implying that in this etching time-range the residues for the three rocks maintain a constant age.

to ensure that the most probable extrusion ages will also be attained in those cases where only 5 min of etching is applied, and because the proper etching time may vary from one basaltic sample to the next. With $1 \sigma= \pm 3.4 \%$ (relative) this error is larger than errors given for individual fractions in Table 3 and is valid for comparison of ages for $5 \mathrm{~min}$ etched magnetic fractions with otherwise determined $\mathrm{K} / \mathrm{Ar}$ extrusion ages. With the ages for $5 \mathrm{~min}$ etched magnetic fractions at hand, we can identify Ar losses or extraneous $\mathrm{Ar}$ in the whole-rocks or in other fractions by comparison of ages or $\mathrm{Ar} / \mathrm{K}$ ratios (Tables 3 and 4).

As examples for the dating approach where only unetched and $5 \mathrm{~min}$ etched whole-rocks and 5 min etched magnetic fractions were analysed, results are presented for five rocks from the Höchstberg locality in this paper (Table 4) and for a further 38 rocks (and their minerals) from the Hocheifel Volcanic Field in Müller-Sohnius et al. (1989).

\section{Application of The Method}

Tephrite HF 44-3 (Table 3): According to the arguments discussed above, we interprete the age value of $38.5 \pm 1.3 \mathrm{Ma}$ from the magnetic fraction etched for $5 \mathrm{~min}$ as the most probable extrusion age of this rock. Compared with this age, whole-rock ages imply Ar loss (unetched and 20 min etched) and extraneous $\operatorname{Ar}(5$ and $10 \mathrm{~min}$ etched). A decision cannot be made as to whether extraneous Ar is inherited or excess Ar. Most likely it is inherited $\mathrm{Ar}$ and stems from upper mantle/lower crustal rocks from which remnants, as amphibole symplectite (Table 2) are found in tephrite HF 44-3. Of all rocks analyzed in this study, this was the only one for which we were able to prepare separates of minerals which can be considered as reliable $\mathrm{Ar}$ chronometers. The ages are $38.6 \pm 0.8 \mathrm{Ma}$ for a $100 \%$ pure kaersutite concentrate and $38.3 \pm 0.8 \mathrm{Ma}$ for a plagioclase/alkali feldspar concentrate from a further sample, HF 44-2, from the same locality (Müller-Sohnius et al., 1989). These control ages agree very well with the age for the $5 \mathrm{~min}$ etched 
magnetic fraction of this rock, thus giving independent support for the reliability of the latter.

Nepheline Basanite HF 108 (Table 3): The age of $5 \mathrm{~min}$ etched magnetic fraction is $32.3 \pm 1.1$ Ma for this rock. The question arises whether 5 min etching was sufficient to remove phases with Ar losses completely, and one could argue that the higher age of $35.6 \mathrm{Ma}$ for the $10 \mathrm{~min}$ etched magnetic fraction better represents the extrusion age for this rock. But as the K-concentration of the latter fraction is comparably low, due to enrichment of xenocrysts with extraneous Ar, we believe that the extrusion age is closer to $32.3 \mathrm{Ma}$ than to $35.6 \mathrm{Ma}$. Whole-rock and nonmagnetic fractions of this rock suffered Ar loss and contain extraneous $\mathrm{Ar}$, respectively.

Olivine Nephelinite HF 364 (Table 3): In this rock all whole-rock and nonmagnetic subsamples have higher ages than the magnetic fractions. The carriers of extraneous Ar are obviously the very abundant xenocrysts (olivine and clinopyroxene, Table 2). Furthermore, the inverse relationship between $\mathrm{K}$ concentrations and ages of the nonmagnetic fractions is indicative of the presence of extraneous Ar. In view of the high abundance of xenocrysts in this rock, the ages of the magnetic fractions agree remarkably well and the age for 5 min etched magnetic fraction of $35.8 \pm 1.2 \mathrm{Ma}$ is probably a good approximation of this rock's extrusion age.
Nepheline Basanites HF 3 and HF 102 (Table 4): From these rocks, unetched whole-rocks and 5 min etched whole-rocks and magnetic fractions were analyzed after it had been established (see above) that relevant age information, and indications of Ar loss or extraneous Ar, can be obtained by considering these fractions only. By comparing results for the 5 min etched magnetic fraction with those for unetched whole-rock, we infer Ar losses from whole-rocks HF 3-1 and HF 3-2. Extraneous Ar is present in all rocks except HF 3-2. This is suggested by relatively high apparent ages for etched whole-rocks, and even higher ones for nonmagnetic fractions, as calculated from the set of data. We can clearly identify two separate eruptive episodes at this locality. Volcanic rocks HF3-1 and 3-11 are approx. 28.6 Ma old. Samples HF 3-K and HF 102, which belong to one petrological type, have an age of approx. 36.6 Ma. Alteration of olivine to "iddingsite/bowlingite" in rock HF 3-K evidently took place soon after eruption and has no influence on the determined age. Rock HF 3-2, from a third sampling site within the Höchstberg area, has an extrusion age of $39.6 \pm 1.3 \mathrm{Ma}$ and belongs to the third eruptive centre recognized by Bussmann (1981).

In a plot $\mathrm{Ar}_{\mathrm{rad}}$ versus $\mathrm{K}$ concentration (not shown), extraneous $\mathrm{Ar}$ contents from 0.052 to $0.250 \times 10^{-6} \mathrm{ccSTP} / \mathrm{g}$ (with a mean value of $\left.0.16 \pm 0.07(1 \sigma) \times 10^{-6} \mathrm{ccSTP} / \mathrm{g}\right)$ for an end component with $\mathrm{K}$ concentration zero may be extrapolated for etched samples HF 3 and HF 102.



Fig. 5. Concentrations of extraneous Ar in a component of nepheline basanites from the Höchstberg locality and corresponding eruption ages. Data for spinel-peridotite xenolith 2-UMX from Nürburg locality are included. Error bars are $1 \sigma$ of the values. Similarities in extraneous Ar concentrations suggest that the same kinds of xenoliths are also the carriers of extraneous Ar in the nepheline basanites. 
In Fig. 5 these derived Ar contents are plotted against the rocks' extrusion ages. Extraneous Ar in a structurally intact spinel-peridotite inclusion in Hocheifel olivine nephelinite from the Nürburg locality (2-UMX, calculated for an age of the host rock of $28 \mathrm{Ma}$; Müller-Sohnius et al., 1989) is also shown. These xenoliths presumably come from the source region of the magmas. Experimental solubility determinations for $\mathrm{Ar}$ in enstatite melts at $1500^{\circ} \mathrm{C}$ (Kirsten, 1968) and in basalt and andesite melts (Hayatsu and Waboso, 1985) show that just above their solidification points, about $0.2 \times 10^{-6} \mathrm{ccSTP} /(\mathrm{g} \times$ atm $\mathrm{Ar})$ remains in the magma. A spinel-peridotite layer extends from 30-50 km depth below the Hocheifel Area (Huckenbolz, 1983). An orthopyroxene/clinopyroxene equilibrium temperature of $1040^{\circ} \mathrm{C}$ is calculated for $50 \mathrm{~km}$ depth (ibid.). Assuming that Henry's law is applicable, and as follows from experiments cited above, Ar partial pressures at the site of incorporation of xenocrysts by magma must then have been approx. 0.8 bar (at approx. $15 \mathrm{kbar}$ total pressure) if extraneous Ar contents of the xenocrysts, as calculated above, are used. Thus we can identify the extraneous $\mathrm{Ar}$ as $\mathrm{Ar}$ inherited during magma contamination with peridotite and pyroxenite fragments.

\section{Conclusions}

The differential etching/magnetic separation approach to whole-rock K-Ar dating enables the determination of extrusion ages of volcanic rocks in cases where rocks suffered $\mathrm{Ar}$ loss or contain extraneous Ar. It seems more suitable than ${ }^{40} \mathrm{Ar}-{ }^{39} \mathrm{Ar}$ stepwise heating for dating whole-rocks with heterogeneous $\mathrm{K}$ distributions and wide ranges of grain sizes, where recoil ${ }^{39} \mathrm{Ar}$ loss and redistribution cannot a priori be ruled out. Etching with hydrofluoric acid causes removal of fine-grained K-rich matrix phases which have lost Ar by diffusion or by chemical alteration. This technique, also reveals extraneous Ar contents in phenocrysts such as olivine and pyroxene which may contribute significently to a rock's Ar inventory. For the basaltic rocks studied, it can be shown that ages obtained on magnetically separated matrix phases which had been etched 5 min with $6 \%$ hydrofluoric acid at room temperature, approximate extrusion ages better than the conventional whole-rock ages do. It is recommended the technique be applied to volcanic whole-rocks whenever suitable minerals for dating purposes cannot be obtained.

Acknowledgments-We wish to thank Dr. H. G. Huckenholz (München) for discussions, and helpful suggestions..... To Dr. H. Köhler (München) we express our gratitude for his administrative guidance through all stages of this investigation. We also thank Drs. A. W. Hofmann (Mainz) and E. K. Jessberger (Heidelberg) for bringing literature concerning etching of basalts to our attention. To Dr. I. Kaneoka (Tokyo) and E. K. Jessberger we want to express our acknowledgments for critically reviewing the manuscript of this article. Thanks to Ms. P. O'Shea (Garching) who corrected our English. Financial sponsorship of one of us (P.H.) by "Deutsche Forschungsgemeinschaft" for parts of this study is acknowledged.

\section{REFERENCES}

Bussmann, E. (1981) Vergleichende strukturgeologische, photo-geologische und vulkanologische Untersuchungen im Raum Ulmen/Eifel. Unpublished Diploma-Thesis, University of Mainz, $135 \mathrm{pp}$.

Dalrymple, G. B. and Lanphere, M. A. (1974) ${ }^{40} \mathrm{Ar}-$ ${ }^{39} \mathrm{Ar}$ age spectra of some undisturbed terrestrial samples. Geochim. Cosmochim. Acta 42, 17211734.

Evernden, J. F. and Curtis, G. H. (1965) Potassiumargon dating of late Cenozoic rocks in East Africa and Italy. Current Anthropology 6, 343-385.

Fuhrmann, U. Lippolt, H. J. and Hess, J. C. (1987) Examination of some proposed $\mathrm{K}-\mathrm{Ar}$ standards: ${ }^{40} \mathrm{Ar} /{ }^{39} \mathrm{Ar}$ analyses and conventional $\mathrm{K}-\mathrm{Ar}$ data. Chem. Geol. (Isot. Geosc. Sect.) 66, 41-55.

Gislason, S. R. and Eugster, H. P. (1987) Meteoric water-basalt interaction I: A laboratory study. Geochim. Cosmochim. Acta 51, 2827-2840.

Hayatsu, A. and Waboso, C. E. (1985) The solubility of rare gases in silicate melts and implications for K-Ar dating. Chem. Geol. (Isot. Geosc. Sect.) 52, 97-102.

Horn, P., Müller-Sohnius, D. and Schult, A. (1988) Potassium-argon ages on a Mesozoic tholeiitic dike 
swarm in Rio Grande do Norte, Brazil. Rev. Bras. Geocienc. 18 (1), 50-53.

Horn, P., Jessberger, E. K., Kirsten, T. and Richter, H. (1975) ${ }^{39} \mathrm{Ar}-{ }^{40} \mathrm{Ar}$ dating of lunar rocks: Effects of grain size and neutron irradiation. Proc. 6th Lunar. Sci. Conf., 1563-1591.

Huckenholz, H. G. (1983) Tertiary volcanism of the Hocheifel Area.: Plateau Uplift, K. Fuchs et al. eds., 121-128.

Huckenholz, H. G. and Büchel, G. (1988) Tertiärer Vulkanismus der Hocheifel (Exkursionsführer). Fortschr. Miner. 66, Beih. 2, 43-82.

Huneke, J. C. and Smith, S. P. (1976) The realities of recoil: ${ }^{39} \mathrm{Ar}$ recoil out of small grains and anomalous age patterns in ${ }^{39} \mathrm{Ar}-{ }^{40} \mathrm{Ar}$ dating. Proc. 7th Lunar Sci. Conf. Suppl. 7, Geochim. Cosmochim. Acta, 2, 1987-2008.

Kaneoka, I. (1971) K-Ar ages of seamounts along the Japan Trench and the effect of acid leaching on the $\mathrm{K}-\mathrm{Ar}$ age of a dredged submarine rock. Geochem. J. 5, 113-120.

Kirsten, T. (1968) Incorporation of rare gases in solidifying enstatite melts. J. Geophys. Res. 73, 28072810.

Müller-Sohnius, D., Horn, P. and Huckenholz, H. G. (1989) K-Ar Datierungen an Tertiären AlkaliVulkaniten der Hocheifel, W.-Deutschland. Chem.
Erde. 1, in press.

Saradeth, S., Soffel, H. C., Horn, P., MüllerSohnius, D. and Schult, A. (1989) Infracambrian and Phanerozoic pole positions and potassiumargon ages from the East Sahara Craton. Geophys. $J$. in press.

Seidemann, D. (1978) ${ }^{40} \mathrm{Ar}-{ }^{39} \mathrm{Ar}$ studies of deep-sea igneous rocks. Geochim. Cosmochim. Acta 42, 17211734.

Shimizu, N. (1974) An experimental study of the partitioning of $\mathrm{K}, \mathrm{Rb}, \mathrm{Cs}, \mathrm{Sr}$ and $\mathrm{Ba}$ between clinopyroxene and liquid at high pressures. Geochim. Cosmochim. Acta 38, 1784-1798.

Turner, G. and Cadogan, P. H. (1974) Possible effects of ${ }^{39} \mathrm{Ar}$ recoil in ${ }^{40} \mathrm{Ar}-{ }^{39} \mathrm{Ar}$ dating. Proc. 5th Lunar Sci. Conf. Suppl. 5, Geochim. Cosmochim. Acta, 2, 1601-1615.

Watson, E. B., Ben Othman, D., Luck, J. M. and Hofmann, A. W. (1987) Partitioning of U, Pb, Cs, $\mathrm{Yb}, \mathrm{Hf}, \mathrm{Re}$ and Os between chromian diopsidic pyroxene and haplobasaltic liquid. Chem. Geol. 62, 191-208.

Wieler, R., Baur, H. and Signer, P. (1986) Noble gases from solar energetic particles revealed by closed system stepwise etching of lunar soil minerals. Geochim. Cosmochim. Acta 50, 1997-2017. 